\title{
Relação entre esgotamento e satisfação em jovens praticantes desportivos
}

\author{
António Rosado ${ }^{1}$ \\ Isabel Mesquita ${ }^{2}$ \\ Abel Correia ${ }^{1}$ \\ Carlos Colaço ${ }^{1}$
}

\author{
${ }^{1}$ Faculdade de Motricidade Humana \\ Universidade Técnica de Lisboa \\ Portugal \\ ${ }^{2}$ Faculdade de Desporto \\ Universidade do Porto \\ Portugal
}

\section{RESUMO}

O presente estudo procura estabelecer a relação entre esgotamento e satisfação em praticantes desportivos. A amostra era constituída por 266 praticantes, 213 do género masculino e 53 do feminino (média de idades de $20.01 \pm 5.357$ ). Os participantes responderam às versões portuguesas de duas escalas de avaliação [Athlete Burnout Questionnaire de Raedeke \& Smith ${ }^{(25)}$ e Athlete Satisfaction Questionnaire (Riemer \& Chelladurai(28) . Realizou-se a análise de componentes principais e a análise da consistência interna dos factores. Os resultados evidenciam suporte parcial para a validade e fidelidade da escala de esgotamento quando usada com a população de jovens desportistas portugueses e um suporte global para as dimensões da escala de satisfação. Os resultados evidenciam níveis absolutos elevados de satisfação em todas as dimensões e níveis baixos a moderados de esgotamento, sendo os níveis mais elevados de satisfação encontrados entre os praticantes do género feminino e entre os praticantes seniores. Considerando a totalidade da amostra, verifica-se que a satisfação é, em parte, predita pelo esgotamento embora essa associação seja, no essencial, fraca e relativa a uma dimensão particular do esgotamento. As variáveis género e nível de prática moderam as relações entre satisfação e esgotamento.

Palavras-chave: esgotamento, satisfação

\begin{abstract}
Relationship between burnout and satisfaction in young sports practitioners

The present study aims to establish the relationship between burnout and athlete sport satisfaction. Two hundred sixty six participants from different sports participated in the study. Specifically, the sample included: 213 males and 53 females (mean age $=20.01 \pm 5.357$ ). They completed the Portuguese versions of two scales, assessing Athlete Burnout Questionnaire [Raedeke \& Smith, (25)] and Athlete Satisfaction Questionnaire (Riemer \& Chelladurai, 28). Principal components factor was performed and internal consistency of the subscales was determined by calculating Cronbach's Coefficient Alpha. This investigation found partial support for the validity and reliability of Athlete Burnout Questionnaire when used with a youth Portuguese sport population and a global support for the validity and reliability of Athlete Satisfaction Questionnaire. Results showed high levels of satisfaction and low levels of burnout between the athletes. The two measures are relatively independents but emotional and physical exhaustion can predict dissatisfaction. Higher levels of satisfaction were found for female athletes and for seniors. Gender and age level moderated the relationship between satisfaction and burnout.
\end{abstract}

Key-words: burnout, satisfaction 


\section{INTRODUÇÃO}

A satisfação é uma parte integral da participação e da apreciação do desporto. Sem satisfação, os atletas virar-se-iam para outras potenciais fontes de sucesso e prazer. A satisfação em desporto pode ser definida como "um estado afectivo positivo resultante de uma complexa avaliação das estruturas, processos e produtos associados com a experiência desportiva"(28 p.135). Por outras palavras, a satisfação é “a diferença entre a percepção do que os atletas receberam e o que eles querem"(7 p. 135). Quanto maior a disparidade entre o que se quer e o que se obtém, maior a insatisfação experienciada, sendo o nível de satisfação um indicador dos sentimentos do atleta sobre os ambientes da equipa desportiva(7).

Riemer \& Chelladurai(28) estabeleceram critérios específicos para classificar as diferentes vertentes da satisfação em desporto. Em primeiro lugar, a satisfação devia estar relacionada com os resultados, como ganhar ou alcançar os objectivos definidos, e com os processos que resultam nesses produtos (por ex., a liderança). Em segundo lugar, a satisfação devia reflectir processos e resultados individuais e grupais ou de equipa. Esta ideia suporta-se na noção de que certos resultados desejados pelos indivíduos podem ser alcançados, unicamente, pela performance ou pelo esforço dos seus companheiros de equipa(28). Consequentemente, um atleta pode desenvolver atitudes face à equipa diferenciadas das atitudes relativamente a si mesmo. Finalmente, um terceiro critério de classificação afirma que a satisfação deve ser analisada da dupla perspectiva das tarefas e dos processos e resultados sociais.

Apesar da satisfação ter sido objecto de particular atenção na área da dinâmica de $\operatorname{grupos}^{(5,8)}$, tem existido pouca investigação para desenvolver medidas adequadas deste constructo. A aproximação metodológica típica tem sido a utilização de um só item para medir uma ou mais facetas da satisfação com o desporto $(5,28,30)$. Além de que estes instrumentos, muitas vezes, avaliam a satisfação global sem estabelecer a natureza da multidimensionalidade da sua construção. Como resultado, o questionário de satisfação do atleta [ASQ] ${ }^{(28)}$ foi desenvolvido para ultrapassar esta limitação operacional. Chelladurai, Inamura, Yamaguchi, Oinuma \& Miyauchi(9) demonstraram que a performance é uma parte signi- ficativa da satisfação do atleta, consequentemente, qualquer factor que possa influenciar a performance (quer a nível individual, quer a nível da equipa) pode, também, directa ou indirectamente, induzir o nível de satisfação do atleta.

No desporto, a satisfação tem sido estudada em conjunto com diversas variáveis, nomeadamente, a liderança $(5,9,11,15,20,27,29,30,32,36)$. Diversos académicos da psicologia do desporto incluíram a satisfação do atleta como uma variável de sucesso no seu trabalho. Por exemplo, o modelo multidimensional de liderança $(4,6)$ inclui a satisfação como uma variável de sucesso, a par da performance.

A satisfação tem sido fortemente relacionada com o esgotamento na literatura profissional e educacional, com níveis elevados de insatisfação manifestadas a altos níveis de esgotamento(1). Similarmente, Lee e Ashford(21), referiram uma relação negativa entre satisfação e exaustão emocional confrontada com a despersonalização ou a realização pessoal.

Nos últimos anos, o termo esgotamento começou a aparecer na comunidade desportiva, com crescente frequência $(3,12,13,24,26,34,33)$. Atletas de elite abandonaram o desporto no auge das suas carreiras, sustentando que estavam esgotados, estado que os levava ao abandono da modalidade(31). Esta situação levou a que treinadores de todos os níveis começassem a discutir os perigos do esgotamento. A ideia subjacente nos modelos teóricos sobre o esgotamento é a de que o atleta se encontra submetido a uma enorme variedade de elementos stressantes (sociais, afectivos, de treino, competitivos, etc.), sem capacidade de implementar estratégias de "combate" suficientes e que, consequentemente, vão levar ao síndrome de esgotamento(22). Para Raedeke e Smith(25), o esgotamento é um síndrome tridimensional caracterizado pelo esgotamento emocional, a despersonalização e a baixa realização pessoal. A dimensão de exaustão físico/emocional parece estar associada às exigências do treino e da competição; já a reduzida percepção da dimensão de realização pessoal penaliza os sentimentos dos atletas no que respeita ao seu crescimento e realização pessoal nas suas participações desportivas, enquanto a dimensão despersonalização representa a perda de interesse pelo desporto e o consequente desejo de retirada(25). 
O modelo cognitivo-afectivo de Smith(31) é o primeiro modelo explicativo do esgotamento, construído para o contexto desportivo, definindo-o como uma reacção ao stresse crónico. Existem características que são indicadores de síndrome de esgotamento(14, 10) tais como: baixa motivação ou energia; problemas de concentração; perda de desejo de jogar/participar; falta de preocupação; distúrbio do sono; esgotamento físico e mental; auto-estima diminuída; afecto negativo; mudanças de humor; abuso de substâncias; mudança de valores e crenças; isolamento emocional; ansiedade aumentada; altos e baixos; dores de cabeça e depressão.

$\mathrm{Na}$ literatura desportiva muito pouca investigação pode ser encontrada relatando a relação entre a satisfação dos atletas e o esgotamento. Altahayneh(2) indicou que a satisfação dos atletas se encontrava correlacionada negativamente com o esgotamento. Todas as associações resultantes neste estudo suportaram esta hipótese, ou seja, que a variável satisfação correlacionava-se negativa e significativamente com todas as variáveis de esgotamento do atleta. Na verdade, altos níveis de trabalho, sobre pressão, são considerados como uma causa para o esgotamento ${ }^{(23)}$. É racional esperar que, nalgumas dimensões, os atletas que estejam satisfeitos relatem níveis mais baixos de esgotamento do que propriamente aqueles que estão descontentes. No entanto, muito poucos estudos analisaram esse elo; por conseguinte, deveremos ser cautelosos quando interpretamos esses dados, uma vez que a coexistência de esgotamento e satisfação não é incomum(23). Espera-se, também, que essas relações sejam influenciadas pelo género e escalão de formação, que de certa forma poderão moderar a associação satisfação-esgotamento.

$\mathrm{Da}$ análise dos quadros teóricos referenciados ressalta a necessidade de conhecermos os níveis de satisfação e de esgotamento dos praticantes desportivos, de saber se estes níveis variam em função de variáveis como o género e o escalão e, ainda, de aprofundarmos as relações entre satisfação e esgotamento em desporto.

Neste estudo coloca-se a hipótese de existirem entre os atletas níveis elevados de satisfação com as diversas dimensões da prática desportiva e existirem de baixos níveis de esgotamento entre os atletas.

Coloca-se, ainda, a hipótese de existência da associa- ção entre esgotamento e satisfação, de tal maneira que elevados níveis de satisfação se associam a baixos níveis de esgotamento. A nossa hipótese inicial é de que a satisfação dos atletas (com o treino e a instrução, com o tratamento pessoal, com a performance da equipa e com a performance individual) estará negativamente correlacionada com o esgotamento dos atletas pois parece-nos mais provável que atletas satisfeitos relatem níveis mais baixos de esgotamento do que os atletas satisfeitos. A nossa hipótese é, também, que essas relações sejam influenciadas pelo género e escalão de formação, que deverão moderar as relações satisfação-esgotamento.

\section{MÉTODO}

\section{Participantes}

Neste estudo participaram 267 indivíduos dos quais 213 do género masculino e 53 do género feminino, provenientes de vinte e três modalidades, das quais dezasseis são modalidades individuais e sete são modalidades colectivas, com uma média de idades de 20.07 \pm 5.357 . Garantiu-se, assim, uma amostra muito heterógenea no que respeita à proveniência desportiva.

\section{Instrumentos}

Para a realização deste estudo, utilizaram-se os seguintes questionários: Questionário sobre o Esgotamento do Atleta (Athlete Burnout Questionnaire) de Thomas Raedeke e Alan Smith(25) e Questionário sobre a Satisfação do Atleta (Athlete Satisfaction Questionnaire) de Riemer e Chelladurai(28) nas suas adaptações portuguesas. Obteve-se, por tradução, a versão portuguesa de ambos os instrumentos com base na constituição de um painel de peritos ${ }^{(5)}$ com formação avançada em ciências do desporto e 2 licenciados em línguas e literatura inglesa, que procederam a traduções independentes dos instrumentos. As várias fases de confrontação de alternativas de tradução garantiram uma adequada tradução do instrumento à capacidade de compreensão dos destinatários.

A satisfação dos praticantes foi medida pelo ASQ de Riemer e Chelladurai(28). Este questionário mede 15 factores da satisfação dos praticantes (performance individual, performance da equipa, utilização de capacidades, estratégia, tratamento pessoal, treino e 
instrução, contribuição das tarefa de grupo, contribuição social do grupo, ética da equipa, integração da equipa, dedicação pessoal, orçamento, pessoal médico, serviços de suporte académicos e agentes externos) num total de 56 itens. Os praticantes respondem numa escala de 1 a 7 , indicando o valor mais elevado a máxima satisfação. A escala foi devidamente testada quanto à sua fidelidade, validade de construção e estrutura factorial(17).

Neste estudo, a satisfação foi avaliada através da utilização de quatro das 15 sub-escalas do ASQ: satisfação com treino e instrução (3 itens), satisfação tratamento pessoal (5 itens), satisfação com a equipa (3 itens) e satisfação com a performance individual (3 itens). As duas primeiras sub-escalas concentram-se na satisfação com o processo de treino, enquanto que as outras avaliam a satisfação com os resultados associados aos processos de liderança( ${ }^{(28)}$.

A satisfação com o treino e a instrução refere-se à satisfação com o treino e à instrução fornecida pelo treinador. A satisfação com o tratamento pessoal refere-se à satisfação com os comportamentos no treino que directamente afectam o indivíduo e que indirectamente afectam o desenvolvimento de equipa. Esta dimensão inclui o suporte social e o feedback positivo. A satisfação com a equipa refere-se à satisfação do praticante com o nível dos resultados da sua equipa. A performance na tarefa inclui a performance absoluta, a realização de objectivos e as melhorias do desempenho. Finalmente, a satisfação com a performance individual refere-se à satisfação do praticante com o seu desempenho das tarefas. A performance na tarefa inclui a performance absoluta, melhorias na performance e realização de objectivos ${ }^{(28)}$.

Riemer e Chelladurai(28) estimaram a consistência interna (Alfa de Cronbach) entre .78 e .95

(média $=.88$ ). Riemer e Chelladurai também forneceram a evidência da validade de construção do ASQ. Para o efeito utilizaram a análise factorial confirmatória e as correlações de item-score total. As correlações entre as sub-escalas do $\mathrm{ASQ}^{(28)}$, as sub-escalas que medem o constructo "Intenção de Abandono" e "Compromisso de Equipa"(8) e a Escala de Afectividade Negativa fornecem a evidência de validade referida ao critério. Esta escala foi devidamente testada quanto à fidelidade, validade de construção e estrutura factorial $(17,28)$.
Para a amostra actual, obtiveram-se os seguintes valores de fidelidade: .870 (satisfação com a equipa), .895 (satisfação com a performance individual), .950 (satisfação com o Treino/Instrução) e .963 (satisfação com o tratamento pessoal).

O questionário sobre o Esgotamento do Atleta é constituído por 15 questões, numa escala de Likert que varia de quase nunca (1) a quase sempre (5). O conteúdo e a validade de construção do $\mathrm{ABQ}$ foram demonstrados por Raedeke e Smith(25). Quanto à fidelidade, Raedeke e Smith estimaram a coerência interna (alfa de Cronbach) de .91 para a exaustão físico-emocional, .85 para a baixa realização pessoal, e .90 para a desvalorização. Adicionalmente, as estimativas de fidelidade com o teste-reteste conseguidas numa amostra de corredores de corta-mato nas três subescalas foram .92 para a exaustão físicoemocional, .86 para a baixa realização pessoal e .92 para a desvalorização. No questionário do esgotamento, através da análise factorial de componentes principais, pelo método varimax, confirmou-se a existência das três dimensões previstas: esgotamento físico e emocional, despersonalização e baixa realização pessoal explicando $53,97 \%$ da variância total. Para a amostra actual, a fidelidade da escala de esgotamento é de .849 para a exaustão físico-emocional e de .749 para a desvalorização. Um factor (realização pessoal) teve fidelidade inferior a .70 e não foi incluído nas análises subsequentes.

\section{Procedimentos}

Todos os atletas, das diferentes modalidades, foram contactados pessoalmente para que fosse autorizada a aplicação dos questionários, com a respectiva explicação introdutória sobre a finalidade e forma de preenchimento, dos mesmos. Após este procedimento, os atletas preencheram os respectivos questionários, sendo sempre garantido o anonimato e a confidencialidade dos resultados. Todos os participantes preencheram os questionários numa sala tranquila sem terem presentes companheiros de equipa. O preenchimento dos questionários demorou aproximadamente 20 minutos. Os questionários foram contrabalançados para se eliminar o efeito de ordenação. Os procedimentos de correlação usados envolveram a realização da prova $r$ de Pearson e a regressão múltipla para a totalidade da amostra 
tendo sido estabelecido um nível de significância de $p<.05$. Para além do estudo correlativo procedeuse, ainda, a uma comparação dos resultados dos testes de satisfação e esgotamento em função do género e do escalão competitivo, tendo-se utilizado a estatística ANOVA, após verificação dos pressupostos de normalidade e homogeneidade das variâncias.

Esses procedimentos foram efectuados através do programa de análise estatística, SPSS 15.0.

\section{RESULTADOS}

As estatísticas descritivas apresentadas no Quadro 1 pretendem caracterizar a amostra global em medidas de tendência central e de dispersão.

As médias descritas representam valores baixos de esgotamento, quer no que se refere ao esgotamento global, quer no que se refere às duas dimensões de esgotamento retidas para análise; a exaustão físicoemocional e a desvalorização. Já no que se refere à satisfação, encontrámos valores médios a elevados de satisfação entre os praticantes inquiridos.

A mesma análise foi realizada em função da variável género. Como se pode constatar (Quadro 2), os praticantes masculinos apresentam valores mais elevados de esgotamento, quer global, quer no que se refere à exaustão físico-emocional quer à desvalorização. Já as praticantes apresentam valores mais elevados de satisfação com a prática desportiva em todas as dimensões de análise consideradas.

A comparação dos dois grupos revela diferenças significativas para a satisfação global, para a satisfação com a equipa, para a satisfação com o tratamento pessoal e a performance individual, sendo favoráveis às participantes.

No que se refere ao esgotamento, não se encontraram diferenças significativas entre os dois géneros. No que se refere aos escalões etários, considerando uma divisão em escalões de formação e escalão sénior, verificámos maiores níveis de satisfação e de esgotamento global para os seniores, bem como maiores níveis de exaustão física e emocional e de desvalorização e níveis mais elevados de satisfação com a equipa, com o tratamento pessoal, com a performance individual e com o treino e a instrução do que os escalões de formação.

As comparações ente os dois escalões etários vem revelar, no entanto, que essas diferenças não são estatisticamente significativas para o valor global do esgotamento, nem para a exaustão físico-emocional, mas, sim, para a desvalorização, sentindo os seniores, de forma significativamente mais intensa a influência desta dimensão do esgotamento. No entanto, apresentam, sistematicamente valores mais elevados de satisfação do que os praticantes dos escalões de formação.

No procedimento estatístico para verificar qual a relação entre a satisfação e o esgotamento obtiveram-se os resultados apresentados no Quadro 6. Como se esperaria, as correlações entre as diversas dimensões da satisfação são significativas e positivas o mesmo acontecendo com as diversas dimensões do esgotamento.

Considerando a totalidade da amostra de praticantes verifica-se, no essencial, a ausência de correlação entre as diversas dimensões da satisfação e do esgotamento, com excepção para a correlação entre a satisfação com o treino e a instrução e a exaustão físico-emocional. Sendo positiva essa relação $(\mathrm{r}=.138, \mathrm{p}=.025)$ tal significa que elevados níveis de satisfação com o treino e a instrução potenciam a percepção de níveis superiores de exaustão física e emocional.

Quando as matrizes de correlações consideraram os dois níveis da variável género verificou-se, para o sexo feminino, uma ausência total de correlação entre as diversas medidas de satisfação e as medidas de esgotamento. Já no que se refere aos praticantes masculinos a satisfação com o treino e a instrução correlaciona-se positivamente com o Esgotamento Global $(\mathrm{r}=.145, \mathrm{p}=.037)$ e com a Exaustão Física e Emocional $(\mathrm{r}=.177, \mathrm{p}=.011)$.

Por outro lado, os escalões de formação apresentam correlações significativas entre a Satisfação com o Treino e a Instrução com o Esgotamento $(r=.25$, $\mathrm{p}=.008)$, a Exaustão Físico-Emocional $(\mathrm{r}=.233$, $\mathrm{p}=.015)$ e a desvalorização $(\mathrm{r}=.202, \mathrm{p}=.037)$, de tal modo que a satisfação com o treino e a Instrução se correlaciona positiva e significativamente com todas as variáveis do esgotamento consideradas. Acresce, ainda, que a satisfação com a equipa se correlaciona positivamente com a exaustão físico-emocional $(\mathrm{r}=.233, \mathrm{p}=.015)$ e que a satisfação com a performance individual se correlaciona, também, com a exaustão $(r=.207, p=.031)$. Diversas medidas de 


\begin{tabular}{|c|c|c|c|c|c|c|}
\hline & \multirow{2}{*}{$\begin{array}{l}\mathbf{N} \\
263\end{array}$} & \multicolumn{2}{|l|}{ Média } & \multicolumn{2}{|c|}{ Desvio-Padrão } & Duadro 1.8 \\
\hline Exaustão física e emocional & & 1.93 & & .709 & & \\
\hline Desvalorização & 262 & 1.92 & & .720 & & \\
\hline Satisfação com a equipa & 265 & 4.25 & & 1.361 & & \\
\hline Satisfação Tratamento Pessoal & 263 & 5.52 & & 2.187 & & \\
\hline $\begin{array}{l}\text { Satisfação com Treino e } \\
\text { Instrução }\end{array}$ & 264 & 4.46 & & 1.823 & & \\
\hline $\begin{array}{l}\text { Satisfação com a Performance } \\
\text { Individual }\end{array}$ & 265 & 4.54 & & 1.496 & & \\
\hline Valor Global da Satisfação & 262 & 4.45 & & 1.513 & & \\
\hline \multirow[t]{2}{*}{ Valor Global do Esgotamento } & 261 & \multicolumn{2}{|l|}{2.25} & \multicolumn{2}{|l|}{.526} & \\
\hline & & & $\mathbf{N}$ & Média & Desvio-Padrão & \\
\hline \multirow[t]{3}{*}{ Valor Global da Satisfação } & \multicolumn{2}{|r|}{ Masculino } & 209 & 4.35 & 1.564 & \\
\hline & \multicolumn{2}{|r|}{ Feminino } & 52 & 4.85 & 1.201 & \\
\hline & \multicolumn{2}{|r|}{ Total } & 261 & 4.45 & 1.510 & \\
\hline \multirow[t]{3}{*}{ Valor Global do Esgotamento } & \multicolumn{2}{|r|}{ Masculino } & 208 & 2.27 & .530 & \\
\hline & \multicolumn{2}{|r|}{ Feminino } & 52 & 2.17 & .508 & \\
\hline & \multicolumn{2}{|r|}{ Total } & 260 & 2.25 & .526 & \\
\hline \multirow[t]{3}{*}{ Exaustao fisica e emocional } & \multicolumn{2}{|r|}{ Masculino } & 210 & 1.95 & .722 & \\
\hline & \multicolumn{2}{|r|}{ Feminino } & 52 & 1.87 & .655 & \\
\hline & \multicolumn{2}{|r|}{ Total } & 262 & 1.93 & .709 & \\
\hline \multirow[t]{3}{*}{ Desvalorização } & \multicolumn{2}{|r|}{ Masculino } & 209 & 1.93 & .726 & \\
\hline & \multicolumn{2}{|r|}{ Feminino } & 52 & 1.88 & .706 & \\
\hline & \multicolumn{2}{|r|}{ Total } & 261 & 1.92 & .721 & \\
\hline \multirow[t]{3}{*}{ Satisfação com a equipa } & \multicolumn{2}{|r|}{ Masculino } & 211 & 4.14 & 1.370 & \\
\hline & \multicolumn{2}{|r|}{ Feminino } & 53 & 4.61 & 1.239 & \\
\hline & \multicolumn{2}{|r|}{ Total } & 264 & 4.24 & 1.356 & \\
\hline \multirow[t]{3}{*}{ Satisfação Tratamento Pessoal } & \multicolumn{2}{|r|}{ Masculino } & 210 & 5.38 & 2.252 & \\
\hline & \multicolumn{2}{|r|}{ Feminino } & 52 & 6.04 & 1.799 & \\
\hline & & Total & 262 & 5.51 & 2.183 & \\
\hline Satisfação com Treino e Instrução & & Masculino & 210 & 4.36 & 1.890 & \\
\hline & & Feminino & 53 & 4.83 & 1.477 & \\
\hline & & Total & 263 & 4.45 & 1.821 & \\
\hline Satisfação com a Performance & & Masculino & 211 & 4.44 & 1.538 & \\
\hline & & Feminino & 53 & 4.89 & 1.260 & \\
\hline & & Total & 264 & 4.53 & 1.495 & \\
\hline
\end{tabular}

Quadro 2. Estatísticas Descritivas das variáveis de Satisfação e

Esgotamento de acordo com o Género 
Quadro 3. Valores da Anova para as comparações entre Satisfação e Esgotamento em função do Género
Quadro 4. Estatísticas Descritivas das variáveis de Satisfação e Esgotamento de acordo com o Escalão

\begin{tabular}{lllll}
\hline & Soma de & df & F & Sig. \\
& Quadrados & & & .032 \\
\hline Valor Global da Satisfação & 10.419 & 1 & 4.632 & .217 \\
Valor Global do Esgotamento & .424 & 1 & 1.531 & .483 \\
Exaustão física e emocional & .249 & 1 & .494 & .666 \\
Desvalorização & .097 & 1 & .187 & .024 \\
Satisfação com a equipa & 9.335 & 1 & 5.156 & .048 \\
Satisfação Tratamento Pessoal & 18.550 & 1 & 3.934 & .096 \\
Satisfação com Treino e Instrução & 9.217 & 1 & 2.796 & .049 \\
Satisfação com a Performance Individual & 8.666 & 1 & 3.917 & \\
\hline
\end{tabular}

\begin{tabular}{|c|c|c|c|}
\hline Variáveis & & Média & Desvio-padrão \\
\hline \multirow[t]{3}{*}{ Valor Global da Satisfação } & Sénior & 4.95 & 1.017 \\
\hline & Escalão de formação & 3.73 & 1.803 \\
\hline & Total & 4.45 & 1.513 \\
\hline \multirow[t]{3}{*}{ Valor Global do Esgotamento } & Sénior & 2.28 & .493 \\
\hline & Escalão de formação & 2.21 & .569 \\
\hline & Total & 2.25 & .526 \\
\hline \multirow[t]{3}{*}{ Exaustão física e emocional } & Sénior & 1.92 & .651 \\
\hline & Escalão de formação & 1.95 & .785 \\
\hline & Total & 1.93 & .709 \\
\hline \multirow[t]{3}{*}{ Desvalorização } & Sénior & 2.02 & .710 \\
\hline & Escalão de formação & 1.79 & .714 \\
\hline & Total & 1.92 & .720 \\
\hline \multirow[t]{3}{*}{ Satisfação com a equipa } & Sénior & 4.56 & 1.152 \\
\hline & Escalão de formação & 3.80 & 1.505 \\
\hline & Total & 4.25 & 1.361 \\
\hline \multirow[t]{3}{*}{ Satisfação Tratamento Pessoal } & Sénior & 6.17 & 1.675 \\
\hline & Escalão de formação & 4.59 & 2.487 \\
\hline & Total & 5.52 & 2.187 \\
\hline \multirow[t]{3}{*}{ Satisfação com Treino e Instrução } & Sénior & 5.07 & 1.204 \\
\hline & Escalão de formação & 3.60 & 2.181 \\
\hline & Total & 4.46 & 1.823 \\
\hline \multirow[t]{3}{*}{ Satisfação com a Performance Individual } & Sénior & 5.09 & 1.083 \\
\hline & Escalão de formação & 3.76 & 1.652 \\
\hline & Total & 4.54 & 1.496 \\
\hline
\end{tabular}




\begin{tabular}{lllll}
\hline & $\begin{array}{l}\text { Soma de } \\
\text { Quadrados }\end{array}$ & df & F & Sig. \\
\hline Valor Global da Satisfação & 93.571 & 1 & 48.264 & .000 \\
Valor Global do Esgotamento & .328 & 1 & 1.184 & .277 \\
Exaustão física e emocional & .096 & 1 & .191 & .662 \\
Desvalorização & 3.436 & 1 & 6.770 & .010 \\
Satisfação com a equipa & 38.136 & 1 & 22.221 & .000 \\
Satisfação Tratamento Pessoal & 159.219 & 1 & 37.981 & .000 \\
Satisfação com Treino e Instrução & 137.437 & 1 & 48.849 & .000 \\
Satisfação com a Performance Individual & 112.944 & 1 & 62.071 & .000 \\
\hline
\end{tabular}

Quadro 5. Valores da Anova para as comparações entre Satisfação e Esgotamento em função do Escalão

Quadro 6. Correlações entre Satisfação e Esgotamento

\begin{tabular}{|c|c|c|c|c|c|c|c|}
\hline & & Exaustão & Desvalorização & $\begin{array}{l}\text { Satisfação } \\
\text { equipa }\end{array}$ & $\begin{array}{l}\text { Satisfação } \\
\text { Tratamento } \\
\text { Pessoal }\end{array}$ & $\begin{array}{l}\text { Satisfação } \\
\text { Treino e } \\
\text { Instrução }\end{array}$ & $\begin{array}{l}\text { Satisfação } \\
\text { Performance } \\
\text { Individual }\end{array}$ \\
\hline \multirow[t]{3}{*}{ Exaustão } & $r$ & 1 & $.644[* *]$ & .111 & .073 & $.138\left[^{*}\right]$ & .049 \\
\hline & Sig. & & .000 & .072 & .241 & .025 & .432 \\
\hline & $\mathrm{N}$ & 263 & 262 & 263 & 262 & 262 & 263 \\
\hline \multirow[t]{3}{*}{ Desvalorização } & $r$ & $.644[* *]$ & 1 & .017 & .048 & .097 & .019 \\
\hline & Sig. & .000 & & .783 & .444 & .118 & .759 \\
\hline & $\mathrm{N}$ & 262 & 262 & 262 & 262 & 261 & 262 \\
\hline \multirow[t]{3}{*}{ Satisfação equipa } & $r$ & .111 & .017 & 1 & $.733\left[^{* *}\right]$ & $.769\left(^{* *}\right)$ & $.742\left[^{* *}\right]$ \\
\hline & Sig. & .072 & .783 & & .000 & .000 & .000 \\
\hline & $\mathrm{N}$ & 263 & 262 & 265 & 263 & 264 & 265 \\
\hline \multirow{5}{*}{$\begin{array}{l}\text { Satisfação } \\
\text { Tratamento } \\
\text { Pessoal }\end{array}$} & $r$ & .073 & .048 & $.733\left[^{* *}\right]$ & 1 & $.842(* *)$ & $.784\left[^{* *}\right]$ \\
\hline & & & & & & & \\
\hline & & & & & & & \\
\hline & Sig. & .241 & .444 & .000 & & .000 & .000 \\
\hline & $\mathrm{N}$ & 262 & 262 & 263 & 263 & 262 & 263 \\
\hline \multirow{2}{*}{$\begin{array}{l}\text { Satisfação Treino e } \\
\text { Instrução }\end{array}$} & $r$ & $.138\left[^{*}\right]$ & .097 & $.769\left[^{* *}\right]$ & $.842\left[^{* *}\right]$ & 1 & $.819\left(^{* *}\right)$ \\
\hline & Sig. & .025 & .118 & .000 & .000 & & .000 \\
\hline Satisfação & $r$ & .049 & .019 & $.742\left[^{* *}\right]$ & $.784[* *]$ & $.819\left(^{* *}\right]$ & 1 \\
\hline \multicolumn{8}{|l|}{ Performance } \\
\hline Individual & & & & & & & \\
\hline
\end{tabular}

satisfação correlacionam-se, assim, positivamente com diversas medidas de esgotamento nos escalões de formação.

Já no escalão sénior, a Satisfação com o Treino e a Instrução correlaciona-se negativamente quer com o valor global do esgotamento $(r=-.167, \mathrm{p}=.039)$ quer com a Desvalorização $(r=-.169, \mathrm{p}=.0036)$. Tal significa que as relações entre esgotamento e satisfa- ção parecem ser muito influenciadas pelas variáveis género e escalão etário.

No sentido de aprofundar estas relações, procurando perceber em que medida a satisfação global podia ser predita pelas diversas medidas parciais de satisfação e pelas medidas de esgotamento, realizámos uma análise da regressão múltipla (utilizando o método enter) para a totalidade da amostra. 
Quadro 7. Modelo de Regressão para a Satisfação Global

\begin{tabular}{|c|c|c|c|c|c|}
\hline \multirow[t]{2}{*}{ Modelo } & \multicolumn{2}{|c|}{$\begin{array}{l}\text { Coeficientes Não- } \\
\text { standartizados }\end{array}$} & \multirow{2}{*}{$\begin{array}{l}\text { Coeficientes } \\
\text { standartizados } \\
\text { Beta }\end{array}$} & \multirow[t]{2}{*}{$\mathbf{t}$} & \multirow[t]{2}{*}{ Sig. } \\
\hline & $\mathrm{B}$ & Std. Error & & & \\
\hline (Constante) & .064 & .012 & & 5.370 & .000 \\
\hline Exaustão física e emocional & -.014 & .005 & -.007 & -2.936 & .004 \\
\hline Desvalorização & .000 & .005 & .000 & .065 & .948 \\
\hline Satisfação com a equipa & .153 & .003 & .138 & 48.071 & .000 \\
\hline Satisfação Tratamento Pessoal & .307 & .002 & .442 & 130.242 & .000 \\
\hline Satisfação com Treino e Instrução & .230 & .003 & .277 & 73.649 & .000 \\
\hline $\begin{array}{l}\text { Satisfação com a Performance } \\
\text { Individual }\end{array}$ & .228 & .003 & .225 & 69.802 & .000 \\
\hline
\end{tabular}

Variável Dependente: Valor Global da Satisfação

O modelo geral obtido indica que, como se esperava, a satisfação global é predita pelas medidas parciais de satisfação, cujo peso relativo pode agora ser equacionado com base nos valores beta da equação de regressão e, ainda, pela exaustão físico-emocional, com a qual se correlaciona negativamente. A variabilidade associada ao género e ao escalão etário sugeriu a necessidade de equações de regressão específicas para estas duas variáveis. No que se refere ao sexo masculino manteve-se o mesmo modelo (a exaustão a correlacionar-se negativamente com a satisfação global) mas o modelo alterou-se para o género feminino, uma vez que a exaustão físicoemocional deixa de ter expressão significativa como preditora da satisfação $(t=.063, \mathrm{p}=.950)$, o que sublinha a grande independência, no género feminino, entre satisfação e esgotamento.

A análise da regressão considerando os dois escalões etários, seniores e formação, evidencia, no caso dos seniores, que a satisfação global não é predita por nenhuma das variáveis do esgotamento. No caso dos escalões de formação, a exaustão física e emocional é já considerada no modelo $(\mathrm{t}=-3.915, \mathrm{p}=.000)$, apresentando uma correlação negativa com o valor global da satisfação.

\section{DISCUSSÃO}

Os atletas deste estudo apresentam baixos níveis de esgotamento e apresentam elevados níveis de satisfação com todas as componentes da sua experiência desportiva. Na medida em que a satisfação deriva prioritariamente dos aspectos psicológicos e ambientais associados ao atleta $(2,7)$, os resultados do presente estudo mostram efectivamente que, de uma forma geral, a prática desportiva tem proporcionado aos praticantes sentimentos positivos sobre os ambientes da equipa $(2,7)$ e sobre os desempenhos individuais. No presente estudo esta constatação foi particularmente evidente nas equipas sénior e no sexo feminino.

Por outro lado, verificámos que a satisfação dos atletas (treino e instrução, tratamento pessoal, performance da equipa e performance individual) estão altamente correlacionadas. De facto, a satisfação global correlaciona-se positivamente com os diversos factores de satisfação e todas elas entre si. O mesmo acontece para as diversas variáveis do esgotamento, que se correlacionam significativamente entre si, de modo positivo.

A satisfação dos atletas não se correlaciona, no entanto, do mesmo modo com todas as variáveis do 
esgotamento e a variável género e escalão etário parecem influenciar esta relação. No nosso caso, a exaustão físico-emocional aparece como o melhor preditor da satisfação global com as práticas desportivas mantendo com esta uma correlação moderada negativa.

Também Altahayneh(2) encontrou correlações moderadas negativas entre a exaustão físico-emocional e os quatro factores da satisfação. O autor encontrou, ainda, correlações moderadas negativas entre os quatro factores da satisfação com o desporto e a percepção de realização, facto não constatado no nosso estudo. Se esta constatação global tende a confirmar a nossa hipótese de estudo, já quando se considera a moderação das variáveis género e escalão etário, a interpretação deverá ser diferenciada.

No presente estudo foi claro que a variável género interferiu na relação estabelecida entre satisfação e a exaustão física e emocional. Enquanto que nos praticantes estas duas variáveis registaram uma correlação negativa, nas praticantes a relação foi de independência. Ademais, as praticantes apresentaram níveis de satisfação significativamente superiores, podendo encontrar explicação em possíveis diferenças relacionadas com os objectivos de prática desportiva.

Tradicionalmente, o desporto tem sido considerado uma actividade associada ao conceito de masculinidade, no qual prevalece os atributos de forte, agressivo, poderoso e musculoso em contraste com o conceito de feminilidade, o qual se associa a uma relativa fragilidade, submissão e gentileza $(19,35)$. Deste modo, as mulheres tendem a ser menos competitivos que os homens, em ambientes onde os imperativos de rendimento se sobrepõe aos de participação. Tal pode explicar que o sexo feminino, ao privilegiar a participação, a filiação ao grupo, as relações estabelecidas através do desporto, apresente a percepção de níveis de satisfação elevados na prática desportiva. Tais assunções mereceriam no futuro serem confirmadas ou infirmadas pela investigação.

No que se refere aos escalões etários, considerando uma divisão em escalões de formação e escalão sénior, verificámos maiores níveis de satisfação e de esgotamento global para os seniores, bem como maiores níveis de exaustão física e emocional e de desvalorização e níveis mais elevados de satisfação com a equipa, com o tratamento pessoal, com a per- formance individual e com o treino e a instrução do que os escalões de formação.

Relativamente aos escalões etários foi claro que, enquanto nos seniores a satisfação global não foi predita por nenhuma variável do esgotamento, nos iniciados verificou-se uma correlação negativa da exaustão física e emocional com a satisfação. O facto de os seniores apresentarem maior esgotamento e satisfação, embora parecendo paradoxal e contrariando alguma literatura, pode se dever à importância conferida aos objectivos de rendimento em oposição aos objectivos de participação comuns nos escalões de formação. A auto-superação, a transcendência pessoal no ultrapassar dos limites da performance pode, de facto, explicar o facto dos atletas se sentirem mais satisfeitos quando estão esgotados, porquanto o cansaço físico é um indicador de autosuperação.

De facto, os objectivos de prática desportiva podem explicar estas diferenças. Sendo que no escalão sénior imperam os objectivos de rendimento, onde a auto-superação constante dos limites de performance é uma prerrogativa incontornável, é natural que a satisfação não dependa do desgaste emocional e físico dos praticantes mas mais de outros aspectos como seja o sucesso na competição, o reconhecimento social, etc. De facto, a vivência de uma prática deliberada altamente estruturada com o objectivo explícito de ultrapassar as debilidades e de optimizar o rendimento ${ }^{(16)}$, torna a experimentação de níveis de exaustão física e emocional elevados algo natural, resultante das elevadas exigências competitivas impostas aos praticantes.

Contrariamente, nos iniciados, por coincidir com a fase inicial da prática organizada, onde o prazer da participação(35) e o desenvolvimento do espírito de equipa, a aquisição de competências e a possibilidade de competir são os motivos indicados pelos jovens para praticarem desporto federado(18) é plausível que a experimentação de níveis de exaustão física elevada induzam baixos níveis de satisfação. Seria interessante, em futuras pesquisas analisar a consistência e estabilidade das possíveis razões apontadas para a relação entre satisfação e exaustão física e emocional em função do escalão de prática. Em suma, o estudo realizado indicou que os níveis de esgotamento podem ser independentes dos níveis 
de satisfação, embora a questão não tenha uma resposta única, presente o efeito de diversas variáveis mediadoras cujo efeito terá de ser melhor compreendido. Futuramente, importa aprofundar, as relações entre satisfação e esgotamento.

A pesquisa futura deverá estudar os efeitos do esgotamento dos atletas na intenção de abandono e no próprio abandono e estudos comparativos e interculturais devem ser conduzidos para determinar as similaridades e diferenças de diversas características dos treinadores e dos atletas, em função de diversas determinantes sócio-culturais. A pesquisa deve, ainda, examinar as exigências pessoais e situacionais dos diversos tipos de desportos e níveis competitivos de modo a se poder determinar, nestes contextos, as relações entre satisfação e esgotamento. Uma maior compreensão dos mecanismos que influenciam o esgotamento e a satisfação dos atletas pode ajudar a desenvolver métodos mais efectivos de treino.

Beneficiando do estudo, directores e administradores desportivos deverão ser capazes de detectar estratégias de potenciação da satisfação e de prevenção do esgotamento. Os dados também podem ser benéficos ao sugerir direcções relevantes no desenvolvimento de estratégias de intervenção e de planos de acção. Os treinadores podem desenvolver estratégias de intervenção, alterar climas organizacionais, modificar os seus estilos de liderança e implementar estratégias de compensação para aumentar a satisfação, reduzir o esgotamento do atleta, melhorar as condições de trabalho e criar ambientes mais saudáveis.

\section{CORRESPONDÊNCIA}

\section{António Fernando Boleto Rosado}

Technical University of Lisbon

Faculty of Human Movement

Estrada da Costa, Cruz Quebrada

1495-688 Cruz Quebrada-Dafundo

Lisboa (Portugal)

E-mail: arosado@fmh.utl.pt 


\section{REFERÊNCIAS}

1. Abu-Bader SH (2000). Work satisfaction, burnout, and turnover among social workers in Israel: A causal diagram. International Journal of Social Welfare 9: 191-200.

2. Altahayneh Z (2003). The effects of coach's' behaviors and burnout on the satisfaction and burnout of the athletes.

Unpublished doctoral dissertation. The Florida State University. College of Education.

3. Capel SA, Sisley BL, Desertrain GS (1987). The relationship of role conflict and role ambiguity to burnout in high school basketball coaches. Journal of Sport Psychology 9: 106117.

4. Chelladurai P (1980). Leadership in sport organizations. Canadian Journal of Applied Sport Sciences 5(4): 226-231.

5. Chelladurai P (1984). Discrepancy between preferences and perceptions of leadership behaviour and satisfaction of athletes in varying sports. Journal of Sport Psychology, 6: 27-41.

6. Chelladurai P (1990). Leadership in sports: A review. International Journal of Sport Psychology 21: 328-354.

7. Chelladurai P, Riemer H (1997). A classification of facets of athletic satisfaction. Journal of Sport Management 11: 133159.

8. Chelladurai P, Riemer H (1998). Measurement of leadership in sports. In J. L. Duda (Ed.). Advances in sport and exercise psychology measurement (pp. 227-253). Morgantown, WV: Fitness Information Technology.

9. Chelladurai P, Imamura H, Yamaguchi Y, Oinuma Y, Miyauchi T (1988). Sport leadership in a cross-national setting: The case of Japanese and Canadian university athletes. Journal of Sport and Exercise Psychology 10: 374-389.

10. Chiminazzo J, Montagner P (2004). Treinamento esportivo e burnout. EFdeportes, 78 Retrieved February, 25, 2007, from http://www.efdeportes.com/efd78/burnout.htm.

11. Coffman JP (1999). The community college coach: Leadership practices and athlete satisfaction. Unpublished doctoral dissertation. University of San Diego, CA.

12. Collins KC (2002). An examination of factors influencing entrapment and burnout among collegiate female field hockey and lacrosse coaches. Unpublished doctoral dissertation, The University of North Carolina, Greensboro.

13. Dale J, Weinberg RS (1989). The relationship between coaches' leadership style and burnout. The Sport Psychologist 3: $1-13$.

14. Dosil J (2004). Psicología de la Actividad Física y del Deporte. Madrid: McGraw-Hill.

15. Dwyer JM, Fischer DG (1990). Wrestlers' perceptions of coaches' leadership as predictors of satisfaction with leadership. Perceptual and Motor Skills 71: 511-517.

16. Ericsson A, Krampe T, Tesch-Römer C (1993). The role of deliberate practice in the acquisition of expert performance. Psychological Review 100 (3): 363-406.

17. Eys A, Carron V, Beauchamp R, Bray R (2003). Role ambiguity in sport teams. Journal of Sport and Exercise Psychology 25: 534-550.

18. Fonseca A, Monteiro A, Cunha A (2001). "Que motivos levam os jovens a praticar andebol de competição?”. A FCDEF.UP e a psicologia do desporto. Estudo sobre a motivação. Porto: Faculdade de Ciências do Desporto e de Educação Física da Universidade do Porto.
19. Hargraves J (1986). "Where's the Virtue? Where's the Grace? A discussion of the social production of gender through sport". Theory, Culture and Society, 3 (1): 109-121.

20. Horne T, Carron AV (1985). Compatibility in coach-athlete relationships. Journal of Sport Psychology, 7: 137-149.

21. Lee RT, Ashford BE (1993). A further examination of managerial burnout: Toward an integrated model. Journal of Organizational Behavior 14: 3-20.

22. Maslach C, Jackson SE (1981). The measurement of experienced burnout. Journal of Occupational Behavior 2: 99-113.

23. Onyett S, Pillinger T, Muijen M (1997). Job satisfaction and burnout among members of community mental health teams. Journal of Mental Health 6: 55-66.

24. Raedeke TD (1997). Is athlete burnout more than just stress? A sport commitment perspective. Journal of Sport and Exercise Psychology 19: 396-417.

25. Raedeke TD, Smith AL (2001). Development and preliminary validation of an athlete burnout measure. Journal of Sport and Exercise Psychology 23: 281-306.

26. Raedeke TD, Lunney K, Venables K (2002). Understanding athlete burnout: Coach perspectives. Journal of Sport Behavior 25: 181-206.

27. Riemer HA, Chelladurai P (1995). Leadership and satisfaction in athletics. Journal of Sport and Exercise Psychology 17: 276-293.

28. Riemer HA, Chelladurai P (1998). Development of the Athletic Satisfaction Questionnaire (ASQ). Journal of Sport and Exercise Psychology 20: 127-156.

29. Riemer HA, Toon K (2001). Leadership and satisfaction in tennis: Examination of congruence, gender and ability. Research Quarterly for Exercise and Sport 72(3): 243-256.

30. Schliesman ES (1987). Relationship between the congruence of preferred and actual leader behavior and subordinate satisfaction with leadership. Journal of Sport Behavior, 10: $157-166$

31. Smith RE (1986). Toward a cognitive-affective model of athletic burnout. Journal of Sport Psychology 8: 36-50.

32. Sriboon N (2001). Coach leadership behaviors, team cohesion, and athlete satisfaction in relation to the performance of athletes in the 1999 Rajabhat Games. Unpublished doctoral dissertation, The Florida State University, Tallahassee.

33. Vealey RS, Armstrong L, Comar W, Greenleaf C (1998). Influence of perceived coaching behaviors on burnout and competitive anxiety in female college athletes. Journal of Applied Sport Psychology 10: 297-318.

34. Vealey RS, Udry EM, Zimmerman V, Soliday J (1992). Interpersonal and situational predictors of coaching burnout. Journal of Sport and Exercise Psychology 14: 40-58.

35. Weinberg R, Tenenbaum G, Mckenzie A, Jackson S, Anshel M, Grove R, Fogarty G (2000). Motivation for youth participation in sport and physical activity: relationships to culture, self-reported activity levels, and gender. International Journal of Sports Psychology 31: 321-346.

36. Yusof A (1999). The relationship between transformational leadership behaviors of athletic directors and leadership substitutes variables with the job satisfaction of coaches at NCAA Division I and III institutions. Unpublished doctoral dissertation, The University of Connecticut, Storrs, CT. 